\title{
Development of Self-Awareness After Severe Traumatic Brain Injury Through Participation in Occupation-Based Rehabilitation: Mixed-Methods Analysis of a Case Series
}

\author{
Emmah Doig, Pim Kuipers, Sarah Prescott, Petrea Cornwell, \\ Jennifer Fleming
}

\section{MeSH TERMS}

- activities of daily living

- awareness

- brain injuries

- goals

- patient-centered care

- patient-centered outcome
Emmah Doig, PhD, BOccThy Hons, is NHMRC Post Doctoral Research Fellow, School of Health and Rehabilitation Sciences, University of Queensland, St. Lucia Campus, Brisbane, Queensland, Australia 4067; e.doig@uq.edu.au

Pim Kuipers, PhD, BA Hons, MA, Grad Dip Rehab, is Associate Professor, Centre for Functioning and Health Research, Metro South Health District, Queensland Health, Brisbane, Australia, and Population and Social Health Research Program, Griffith Health Institute, Griffith University, Brisbane, Australia.

Sarah Prescott, B Int Bus, BOccThy Hons, is PhD Student, School of Health and Rehabilitation Sciences, University of Queensland, Brisbane, Australia.

Petrea Cornwell, PhD, B SpPath Hons, is Principal Research Fellow, Metro North Hospital and Health Service, Queensland Health, Chermside, Brisbane, Australia, and School of Applied Psychology and Behavioural Basis of Health, Griffith Health Institute, Griffith University, Mount Gravatt, Brisbane, Australia.

Jennifer Fleming, PhD, BOccThy Hons, is Associate Professor, School of Health and Rehabilitation Sciences, University of Queensland, Brisbane, Australia, and Centre for Functioning and Health Research, Metro South Health District, Queensland Health, Brisbane, Australia.
OBJECTIVE. We examined participation in goal planning and development of self-awareness for people with impaired self-awareness after traumatic brain injury.

METHOD. We performed a mixed-methods study of 8 participants recently discharged from inpatient rehabilitation. Self-awareness was measured using discrepancy between self and significant other ratings on the Mayo-Portland Adaptability Index (MPAl-4) at four time points. We calculated effect size to evaluate the change in MPAI-4 discrepancy over time.

RESULTS. Seven participants identified their own goals. We found a large reduction in mean MPAI-4 discrepancy $(M=8.57, S D=6.59, N=7, d=1.08)$ in the first 6 wk and a further small reduction $(M=$ $5.33, S D=9.09, N=6, d=0.45$ ) in the second 6 wk of intervention. Case data indicated that 7 participants demonstrated some growth in self-awareness.

CONCLUSION. Engagement in occupation-based, goal-directed rehabilitation appeared to foster awareness of injury-related changes to varying extents.

Doig, E., Kuipers, P., Prescott, S., Cornwell, P., \& Fleming, J. (2014). Development of self-awareness after severe traumatic brain injury through participation in occupation-based rehabilitation: Mixed-methods analysis of a case series. American Journal of Occupational Therapy, 68, 578-588. http://dx.doi.org/10.5014/ajot.2014.010785

Q elf-awareness is commonly impaired after traumatic brain injury (TBI) because of damage to the frontal lobe and connecting pathways (Toglia \& Kirk, 2000 ) and is reported to be a consequence of TBI in up to $97 \%$ of cases (Sherer, Bergloff, Levin, et al., 1998). Impaired self-awareness manifests as difficulty recognizing impairments, understanding the implications of impairments, and setting realistic goals for the future (Fischer, Gauggel, \& Trexler, 2004; Fleming \& Strong, 1995; Ownsworth \& Clare, 2006). Further implications include underreporting of impairments (Sherer, Bergloff, Levin, et al., 1998; Toglia \& Kirk, 2000), poor compliance with rehabilitation and failure to observe safety precautions (Lam, McMahon, Priddy, \& Gehred-Schultz, 1988), caregiver distress (Ergh, Rapport, Coleman, \& Hanks, 2002), and poor long-term employment outcomes (Sherer, Bergloff, Levin, et al., 1998). Given the incidence and impact of impaired self-awareness, it is necessary to explore and evaluate rehabilitation approaches that enhance development of self-awareness.

Metacognitive rehabilitation approaches such as feedback interventions, pretask prediction, posttask reflection, and role reversal have been shown to be effective for error awareness and self-regulation after TBI during prescribed, preplanned, multistep tasks such as cooking (Cheng \& Man, 2006; Ownsworth, Fleming, Desbois, Strong, \& Kuipers, 2006; Ownsworth, Quinn, Fleming, Kendall, \& Shum, 2010; Schmidt, Lannin, Fleming, \& Ownsworth, 2011). Several studies have also shown that metacognitive treatment approaches focusing on individual 
occupations, in which tasks are selected according to the client's goals and interests, are effective in improving selfawareness (Fleming, Lucas, \& Lightbody, 2006; Goverover, Johnston, Toglia, \& Deluca, 2007; Landa-Gonzalez, 2001; Toglia, Johnston, Goverover, \& Dain, 2010). Goal planning is central to the rehabilitation process because it guides rehabilitation efforts and is reported to increase resilience, focus and drive effort, and enhance performance (Scobbie, Dixon, \& Wyke, 2011).

In this study, we add to the existing literature about the effectiveness of occupation-based interventions for developing self-awareness after TBI. This study, however, differs from previous studies because the intervention used is underpinned by a structured goal-planning process facilitated by the use of the Canadian Occupational Performance Measure (COPM; Law et al., 1994) and Goal Attainment Scaling (GAS; Kiresuk, Smith, \& Cardillo, 1994) to plan rehabilitation goals.

We piloted a client-centered approach to goal planning using the COPM (Law et al., 1994) and GAS (Kiresuk et al., 1994), followed by an occupation-based intervention targeting identified goals with 14 participants with TBI (Doig, Fleming, Cornwell, \& Kuipers, 2009; Doig, Fleming, Kuipers, \& Cornwell, 2010; Doig, Fleming, Kuipers, Cornwell, \& Khan, 2011). This group of 14 participants included people with impaired self-awareness at baseline according to the Self-Awareness of Deficits Interview (SADI; Doig et al., 2011). Findings indicated that most of the participants self-identified occupational performance problems and perceived their program goals as important. Statistical analysis of group data $(n=14)$ indicated that considerable gains were made in goal achievement and self-perceived performance and satisfaction in goal areas during the intervention compared with a baseline phase (Doig et al., 2010, 2011). Qualitative comments made by participants, their significant others, and therapists also indicated that the benefits of the intervention extended beyond goal performance, and gains in self-awareness were described (Doig et al., 2009). Moreover, although the 14 people with TBI presented with varying levels of self-awareness (ranging from no impairment to severe impairment), gains in goal performance were made irrespective of self-awareness abilities (Doig et al., 2010). These findings were different from what we expected, given our understanding of the implications of impaired self-awareness for engagement in goal planning and rehabilitation.

In this study, therefore, we sought to shed new light on an important clinical question: How did the participants with impaired self-awareness respond to the goalplanning approach and the rehabilitation process? The previous study did not explore engagement in goal planning or evaluate change in self-awareness over the course of the intervention for participants with impaired self-awareness. Given the high degree of participant engagement in goal planning, we considered it important to determine whether the goal-planning approach was beneficial specifically for the participants with impaired self-awareness in identifying meaningful rehabilitation goals. The value of the occupationbased intervention for the development of self-awareness over time for participants with impaired self-awareness at intake to the study was also of interest. The aims of our analysis were to (1) explore the outcome of client-centered goal planning in terms of engagement, perceived goal importance, and client-centeredness of program goals and (2) determine whether changes in self-awareness over the course of the program were made by participants with moderate or severe impairment of self-awareness.

\section{Method}

\section{Design}

Clearance was obtained from the relevant ethics committees, and informed written consent was obtained from participants before commencement of data collection. A mixed quantitative and qualitative analysis of data for a subset of participants with impaired self-awareness was conducted. Goal importance and client-centeredness of goals were evaluated after goals were established. Self-awareness was measured at 4 time points, each 6 wk apart: pre- and postbaseline, midway, and postintervention. Participant engagement in goal planning and development of selfawareness were further explored through analysis of postprogram interviews with participants, significant others, and treating therapists as well as researcher field notes.

\section{Participants}

Participants from the larger group $(n=14)$ were eligible to be included in the study if they presented with either severe impairment (SADI score 7-9/9) or moderate impairment (SADI score 4-6/9) of self-awareness at intake to the original study. The data drawn from this subgroup were the focus of reanalysis to identify those participants who presented with impaired self-awareness according to objective assessment. Participants who had a clinical presentation of chronic amnesia were excluded because of the effect of the memory impairment on ability to reliably self-report functioning and reflect on the rehabilitation program during interviews. Participants were living in the community after having been recently discharged from 
inpatient brain injury rehabilitation at a major metropolitan hospital in Brisbane, Australia.

\section{Measures}

Self-Awareness. The SADI is a structured interview designed to assess intellectual awareness across three domains: self-awareness of deficits, self-awareness of functional implications of deficits, and ability to set realistic goals (Fleming, Strong, \& Ashton, 1996). It is a clinician-rated scale in which the significant other's responses on a checklist can be compared with the participant's responses to assist with assigning SADI scores. Each section is scored on a scale from 0 to 3 giving a total score of 9; higher scores indicate greater impairment of self-awareness. The SADI has demonstrated acceptable interrater reliability (intraclass correlation coefficient $[\mathrm{ICC}]=.82$, Fleming et al., 1996; and .85, Fleming, Strong, \& Ashton, 1998). It also has demonstrated adequate test-retest reliability over a $2-4$-wk period (ICC $=.92$; Simmond \& Fleming, 2003) and has been significantly correlated with the Awareness Questionnaire and work status measures in people with acquired brain injury (ABI; Wise, Ownsworth, \& Fleming, 2005). The SADI was administered at study intake to assess the presence and severity of impairment of intellectual awareness.

The fourth edition of the Mayo-Portland Adaptability Index (MPAI-4) is a 30-item questionnaire designed to plan and evaluate progress in rehabilitation for people with ABI after hospital discharge (Malec \& Lezak, 2008). The MPAI-4 consists of three subscales (Ability, Adjustment, and Participation). Studies have established the MPAI-4 as having high concurrent validity with the Disability Rating Scale ( $r=.81$; Malec \& Thompson, 1994), moderate predictive validity when examining living status at $1 \mathrm{yr}$ follow-up from hospital discharge $(r=.64$; Malec, 2001), and discriminant validity when discriminating between two subgroups of the Ranchos Los Amigos Levels of Functioning Scale (Kruskall-Wallis $=22.07, p<.001$; Malec \& Thompson, 1994). The MPAI-4 has been shown to be highly responsive to change ( $d=1.71$; Malec, 2001) in response to treatment efforts. Participant and significantother MPAI-4 Ability raw subscale scores were used (range $=0[$ no problem] to 48 [severe problem]). Discrepancy scores were calculated by subtracting participant ratings from significant-other ratings, with positive scores suggesting impaired self-awareness and higher scores indicating greater impairment.

Goal Importance and Goal Ownership. The COPM (Law et al., 1994) is a semistructured interview designed to identify problems with occupational performance in the areas of self-care, productivity, and leisure. The COPM was used to identify and measure the importance of the goals to the participants on a scale ranging from 1 (not important at all) to 10 (extremely important). The validity of the COPM has been established for various populations (McColl, Paterson, Davies, Doubt, \& Law, 2000), and the clinical utility of the COPM as a client-centered approach has been demonstrated in brain injury rehabilitation settings (Jenkinson, Ownsworth, \& Shum, 2007; Wressle, Eeg-Olofsson, Marcusson, \& Henriksson, 2002).

The Client-Centredness of Goal Setting Scale (C-COGS; Doig et al., 2011) is a questionnaire developed by the researchers to measure the extent to which the agreed program goals were important and meaningful to the participant, as well as goal ownership. Participants were asked to indicate on a scale ranging from 1 (not important) to 5 (totally important) the extent to which they felt the planned program goals were important and meaningful to them. The extent of ownership of the goals by participants was measured by the amount of agreement, on a scale ranging from 1 (strongly disagree) to 5 (strongly agree), with the statements, "The goals are what I want to work on" and "The goals are what my friend/significant other wants me to work on." A significant-other version was also completed to measure how important the significant others felt the goals were to the participants.

\section{Procedures}

At baseline ( $6 \mathrm{wk}$ before onset of intervention) the SADI was administered, and goals were planned. After goals were established, each participant and his or her significant other completed the C-COGS independently of one other. A researcher who was not involved in delivering the interventions (Doig) visited the participants at 4 time points, each 6 wk apart (pre- and post-6-wk baseline, midway, and postintervention) to administer the MPAI -4 and measure progress on goals. The researcher wrote field notes throughout as a chronological summary of goal planning and follow-up assessment sessions, including correspondence with therapists and informal observations about participants. Semistructured interviews were conducted with participants, their significant others, and therapists at the completion of the interventions to explore their experience of and perceptions of the intervention.

\section{Goal-Planning Procedure}

Individualized, client-centered goals were generated using the COPM, and occupational performance areas of greatest importance to participants became the program goals, which were documented and measured using Goal Attainment 
Scaling (Kiresuk et al., 1994). Goals were planned by a researcher who was an occupational therapist but not involved in providing the interventions. Significant others were present for goal-planning sessions. After initial occupational performance problem areas were identified, the target goals were further established through interviewing or observation of task performance to establish current performance and expected levels of performance by program end.

Intervention. Participants received a 12-wk occupational therapy program addressing their identified goals, underpinned by the person-environment-occupation model (Law et al., 1996). An experienced occupational therapy practitioner provided each participant with the intervention, which occurred in the participant's home and in a day hospital setting, each for 6-wk blocks. According to therapist logs, the interventions specifically involved practice of goal-related tasks, grading and adaptation of tasks guided by task analysis, collaborative implementation of a range of individualized strategies to improve occupational performance, therapist feedback about performance, short-term goal formulation from session to session, homework tasks to consolidate practice of strategies in real-life settings, and weekly review and reflection on performance against shortterm goals.

\section{Data Analysis}

To address the first aim (to explore the outcome of clientcentered goal planning), authors Doig and Kuipers conducted a qualitative analysis of interviews with participants, significant others, and therapists and of field notes using manifest content analysis (Graneheim \& Lundman, 2004). The data were revisited with the a priori question, What was the impact of self-awareness on goal planning and rehabilitation? and content relating to goal planning was summarized. Engagement of participants in goal planning was further explored by descriptive analysis of COPM importance ratings and C-COGS ratings.

To investigate the second aim (i.e., development of self-awareness over the course of the program), we plotted participant and significant-other MPAI-4 Ability subscale ratings were plotted at the 4 time points to map change in congruence over time. Mean discrepancy ratings on the MPAI- 4 Ability subscale at the 4 time points were calculated, and Cohen's $d$ was used to determine the effect size of change between each time point. Cohen's $d$ was calculated using the difference between two means divided by the pooled standard deviation weighted by sample size (Cohen, 1988; Zakzanis, 2001). According to Cohen, a $d$ value of 0.8 or higher represents a large effect; 0.5 , a moderate effect; and 0.2, a small effect. Qualitative analysis of interviews with participants, significant others, and therapists and of researcher field notes was carried out using manifest content analysis (Graneheim \& Lundman, 2004). The qualitative data were revisited with the a priori question, What was the impact of the intervention on self-awareness? Content relating to self-awareness was defined as any statements relating to lack of or growth in awareness of (1) problems or changes since the injury, (2) functional implications of problems or changes since the injury, and (3) need for rehabilitation to address problems or changes.

To ensure rigor, we randomly selected 3 participant names, and their interview and field note data were qualitatively analyzed independently by two researchers (Doig and Kuipers). Analysis involved extraction of content relating to the a priori questions and line-by-line coding to determine the meaning (Graneheim \& Lundman, 2004). The two researchers then met to compare codes and meaning. Of the 29 extracts from the data, 23 were highlighted by both researchers, indicating $79 \%$ agreement between the researchers about which data were representative of the a priori questions. In the six instances in which an extract was highlighted by one researcher but not the other, the extracts were discussed, which led to clarification of selfawareness statements. There was strong consensus on the meaning of the extracted data. Using principles established in this process, one researcher (Doig) completed the remaining data extraction and coding using NVivo10 software (QSR International, Victoria, Australia). The second coder was to be consulted for any ambiguous sections in the remaining transcripts; however, after initial clarification, the coder found no instances of ambiguity.

\section{Results}

Participants were a subset of 6 men and 2 women with moderate $(n=4)$ or severe $(n=4)$ impairment of selfawareness at study intake and their significant others (parents $n=6$, partners $n=2$ ). One participant who was eligible for inclusion according to SADI score was excluded because of the presence of chronic amnesia. The mean age of the participants was $26 \mathrm{yr}(S D=7.8)$ with a mean duration of posttraumatic amnesia of 97 days $(S D=61.7$, missing $n=2)$. Demographic, injury severity, and other relevant data for each participant, which were collected from medical records, are outlined in Table 1.

\section{Goal Planning}

Participant goals are summarized in Table 2. Importance ratings according to the COPM indicated that participants felt their goals were highly important and meaningful to them $(M=8.8, S D=1.72$, range $=4-10)$. 
Table 1. Participant Demographic Information, Injury Characteristics, and Self-Awareness of Deficits Interview Scores at Intake

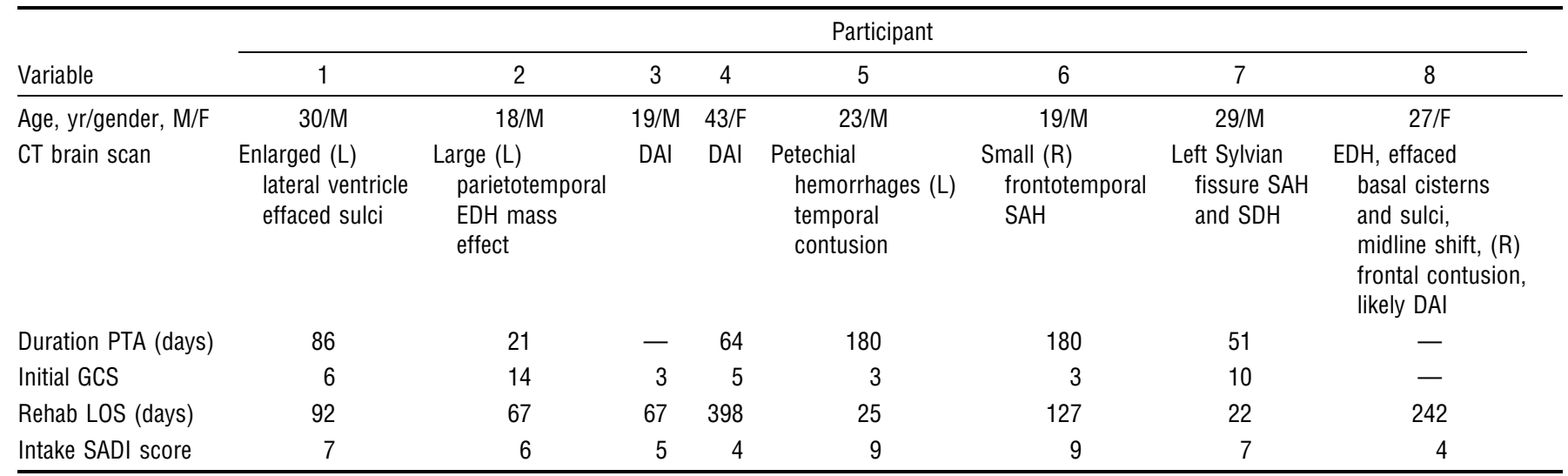

Note. $-=$ missing data; $\mathrm{CT}=$ computed tomography; $\mathrm{DAl}=$ diffuse axonal injury; $\mathrm{EDH}=$ extradural hematoma; $\mathrm{F}=$ female; GCS = Glasgow Coma Scale; $\mathrm{L}=$ left; LOS = length of stay; $M=$ male; PTA = posttraumatic amnesia; $R$ = right; SADI = Self-Awareness of Deficits Interview; SAH = subarachnoid hemorrhage; $\mathrm{SDH}=$ subdural hematoma.

Similarly, participant C-COGS ratings (see Table 2) indicated goals to be of high importance, and there were high levels of agreement from participants that the goals were what they wanted to work on. This finding was consistent with significant-other C-COGS ratings (see
Table 2). One exception was Participant 7, who indicated his goals were important and owned by him, but his mother's responses were contradictory. His mother's C-COGS ratings were more reflective of the goal-planning process for this participant, who was unable to identify any

Table 2. Summary of Program Goals, Canadian Occupational Performance Measure Importance, and Client-Centeredness of Goal Setting Scale Ratings

\begin{tabular}{|c|c|c|c|c|c|}
\hline \multirow[b]{2}{*}{ Participant } & \multirow{2}{*}{$\begin{array}{l}\text { Meaningful Occupational Roles } \\
\text { to Which Goals Related }\end{array}$} & \multirow[b]{2}{*}{ Goal (COPM Importance Rating) } & \multicolumn{3}{|c|}{ C-COGS Ratings } \\
\hline & & & 1 & 2 & 3 \\
\hline \multirow[t]{3}{*}{1} & \multirow[t]{3}{*}{ Driver and student } & Note-taking skills for lectures (10) & $4(\mathrm{P})$ & $4(P)$ & $5(P)$ \\
\hline & & Study skills related to remembering written material (10) & 5 (SO) & $4(\mathrm{SO})$ & $5(\mathrm{SO})$ \\
\hline & & $\begin{array}{l}\text { Using a street directory to plan a driving route (10); } \\
\text { knowledge of road rules (10) }\end{array}$ & & & \\
\hline \multirow[t]{2}{*}{2} & \multirow[t]{2}{*}{ Student } & $\begin{array}{l}\text { Handwriting faster because l'm too slow (10); } \\
\text { note-taking skills (10) }\end{array}$ & $5(P)$ & $5(P)$ & $5(P)$ \\
\hline & & Paying attention to study activities for sustained time (10) & 5 (S0) & 5 (S0) & $5(\mathrm{~S} 0)$ \\
\hline \multirow[t]{2}{*}{3} & \multirow[t]{2}{*}{ Homemaker and artist-hobbyist } & $\begin{array}{l}\text { Dressing lower body (8); use of diary and whiteboard } \\
\text { to aid memory (8) }\end{array}$ & $4(\mathrm{P})$ & $4(P)$ & $3(P)$ \\
\hline & & $\begin{array}{l}\text { Cooking hot meals (6); participating in hobbies more } \\
\text { regularly (4) }\end{array}$ & 4 (SO) & 5 (S0) & $4(\mathrm{SO})$ \\
\hline 4 & Homemaker and mother & $\begin{array}{l}\text { Drying self (9); planning and doing the grocery shopping (9) } \\
\text { Cooking hot meals (9) }\end{array}$ & - & - & - \\
\hline \multirow[t]{2}{*}{5} & \multirow{2}{*}{$\begin{array}{l}\text { Worker (car detailer), gardener, } \\
\text { and pool player (when socializing } \\
\text { with friends) }\end{array}$} & $\begin{array}{l}\text { Participating in pool and being accurate with hitting a pool } \\
\text { ball (8) }\end{array}$ & $4(P)$ & $4(P)$ & $4(\mathrm{P})$ \\
\hline & & $\begin{array}{l}\text { Independence with detailing a car (8); participating in } \\
\text { gardening at home (5) }\end{array}$ & 4 (S0) & 4 (S0) & $4(\mathrm{SO})$ \\
\hline \multirow[t]{2}{*}{6} & \multirow[t]{2}{*}{ Student and apprentice electrician } & Participating in a new hobby (10); study skills (10) & $4(P)$ & $5(P)$ & $3(P)$ \\
\hline & & Using a diary to aid memory and organization (9) & 5 (S0) & 5 (SO) & $5(\mathrm{~S} 0)$ \\
\hline \multirow[t]{3}{*}{7} & \multirow{3}{*}{$\begin{array}{l}\text { Worker (carpentry); missing COPM } \\
\text { importance scores }\end{array}$} & Taking notes to aid memory & $5(P)$ & $5(P)$ & $5(P)$ \\
\hline & & Listening and remembering in everyday situations & 2 (SO) & 2 (SO) & $5(\mathrm{SO})$ \\
\hline & & Participating in leisure activities more regularly & & & \\
\hline \multirow[t]{3}{*}{8} & \multirow[t]{3}{*}{ Homemaker and mother } & $\begin{array}{l}\text { Improve grasp and reach of left hand to be able to play with } \\
\text { son (10) }\end{array}$ & $5(P)$ & $5(P)$ & $4(\mathrm{P})$ \\
\hline & & Be independent with drying back (10) & 5 (SO) & 5 (SO) & 5 (SO) \\
\hline & & Be independent with making breakfast (10) & & & \\
\hline
\end{tabular}

Note. $-=$ missing data; $\mathrm{C}-$ COGS $=$ Client-Centredness of Goal Setting Scale; COPM $=$ Canadian Occupational Performance Measure; $\mathrm{P}=$ participant; SO $=$ significant other. COPM importance ratings range from 1 to 10 , and C-COGS ratings range from 1 to 5 . C-COGS ratings are in response to Question 1, "The goals are important and meaningful to me"; Question 2, "The goals are what I want to work on"; and Question 3, "The goals are what my friend/significant other wants me to work on." 
occupational performance problems during administration of the COPM; thus, goals were formulated, with his permission, by his mother and familiar therapists according to their perception of his problem areas. The other 7 participants were able to identify goals on which they desired to work with varying input from significant others and the therapist. When reflecting on the goal-planning process during the postprogram interview, the mother of Participant 7 stated, "He wasn't able to really set goals to start with ... he didn't have insight into his injury or the depth of it or the problems he was having ... we needed to help him set goals."

All participants agreed to their significant other being present during goal planning and reflected positively about the involvement of their significant other. One exception, Participant 6, despite being agreeable to his mother's participation, later explained they had differences in their perspectives, stating, "[Mum's involvement] was different because she doesn't know exactly what I'm thinking at the time about what I find difficult and what I don't find difficult." One therapist highlighted the value of family involvement in goal setting, "where people don't have good insight because they are really good at helping make things more realistic" (therapist of Participants 2 and 6). A lack of acknowledgment of cognitive changes and awareness of the impact of postinjury changes on tasks such as driving and working was evident. Participants 1,6 , and 7 articulated their frustration at medical restrictions to return to work and driving, externalizing the reasons for restrictions and expressing readiness for return to these tasks. Participants 1, 3, and 5 acknowledged physical changes since their injury but did not acknowledge cognitive changes despite evidence of cognitive changes. Participants 2, 6, and 7 acknowledged cognitive changes to a lesser extent than their significant others, with limited awareness of functional implications of the changes and meaning of problems for their life.

Input from significant others during goal-planning sessions included provision of additional information about the extent of or detail about problems in goal areas (Participants 2, 3, 5 and 8), necessary because of cognitive and communication impairments affecting the participant's ability to initiate or articulate ideas and elaborate on details. Therapist input during goal planning involved asking questions to learn about tasks involved in longterm goals (e.g., return to work, driving) and division of goals into smaller components to be targeted in the shortterm (Participants 1 and 6). One therapist highlighted challenges of setting short-term goals:

It has to be a compromise. ... They'll get maybe 2 steps forward, but in the person's head they want to get to
20 . . . If you just set the goal 2 steps forward to what you think they'll achieve, they won't accept it and therefore they may not engage in it. . . Even if it's not realistic in your terms as a therapist, it needs to be something that they perceive as acceptable to aim for. (therapist of Participants 1, 3, 5, and 8)

\section{Self-Awareness}

Plotted participant and significant-other MPAI-4 Ability ratings are shown in Figure 1. Collateral ratings could not be collected from Participant 8 and her significant other because neither was available to complete the MPAI-4 at the required time points. Visual inspection of the data indicated that participants rated their abilities more highly than did their significant others at all times, with the exception of Participant 5 at time point 4. For Participants $1,4,5$, and 6 , we found a closing of the gap toward greater congruency between participant and significant-other ratings over time.

Although five of the seven significant others' MPAI-4 Ability ratings indicated a pattern of improvement in the participants' abilities over time, six of the seven participant MPAI-4 Ability ratings either remained relatively stable over time or showed a pattern of decline in functioning over time, indicating that participants may have given inflated MPAI-4 ratings at earlier time points. We found a moderate increase $(d=0.65)$ in MPAI-4 discrepancy scores between prebaseline $(M=9.66, S D=$ 3.14, $N=6)$ and postbaseline $(M=10.25, S D=3.3$, $N=4$ ), indicating that significant-other and patient scores became less congruent. At the end of the first $6 \mathrm{wk}$ of the intervention, we found a strong reduction $(M=$ 8.57, $S D=6.59, N=7, d=1.08)$ in MPAI-4 discrepancy scores, and we found a further small reduction $(M=5.33, S D=9.09, N=6, d=0.45)$ at the end of the 12-wk intervention, indicating that significant other and patient scores became more congruent.

All participants who undertook the program made clinically significant improvements in goal achievement, defined by a $\geq 2$-point improvement in COPM performance or attainment of the expected GAS level of achievement (Doig et al., 2011). Six of the participants either achieved or exceeded the expected level of overall achievement (GAS $t \geq 50$ ) by program end, with the exception of Participant 7 (GAS $t=42.7$ ) and Participant 8 (GAS $t=46.7$ ).

Qualitative interview data relating to perspectives of participants, significant others, and therapists about change in participant self-awareness are outlined in Table 3. Qualitative data indicated variable growth in self-awareness. The extent of growth in self-awareness was characterized by 


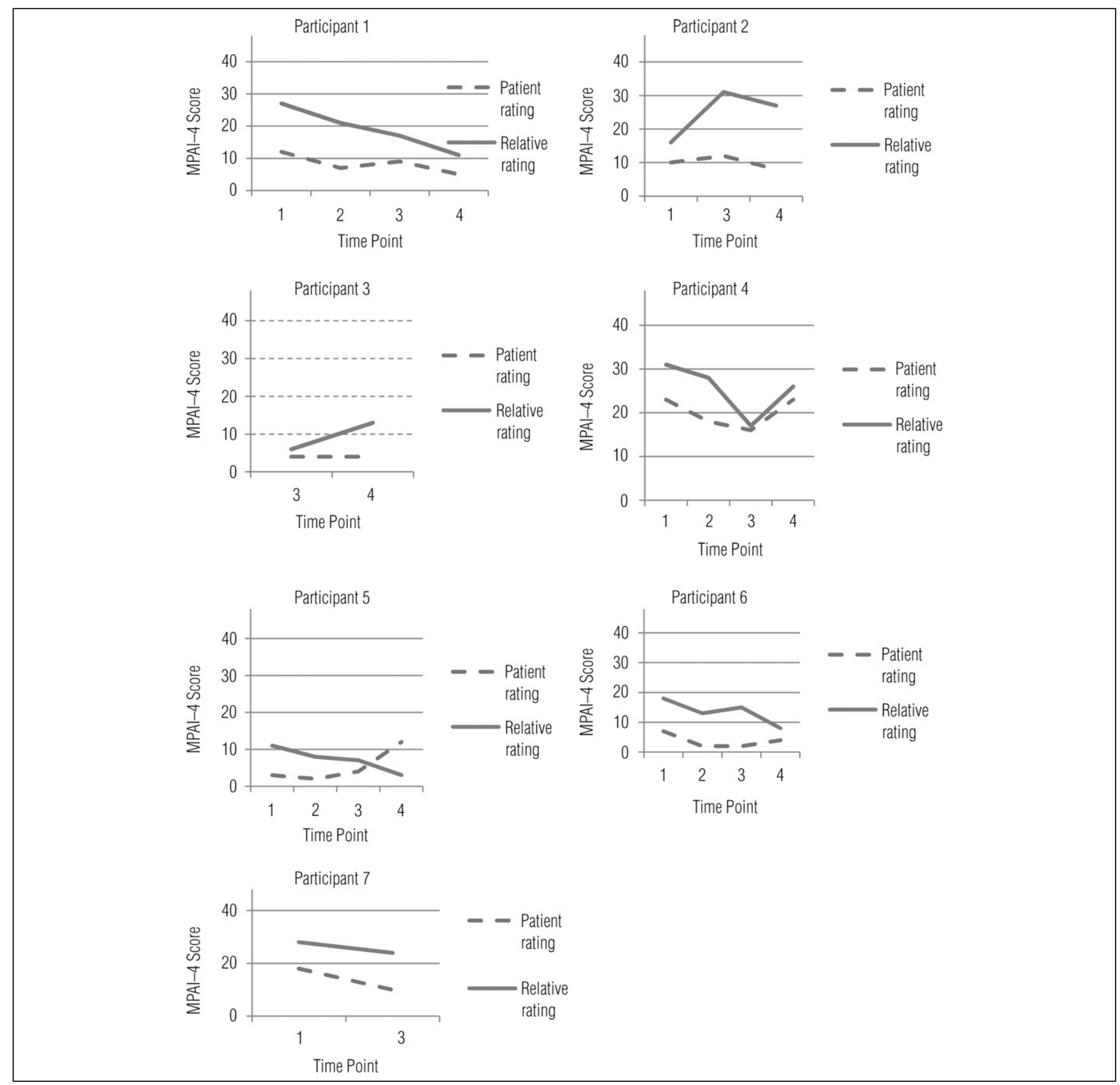

Figure 1. Plotted Mayo-Portland Adaptability Index (4th ed.; MPAI-4) Ability raw scores of self and significant-other ratings at pre- and postbaseline, midway, and postintervention.

Note. X-axis values indicate scores at four time points: $1=$ prebaseline; $2=$ postbaseline; $3=$ midway through 12-wk intervention; $4=$ postintervention. Postbaseline data are missing for Participant 2. Pre- and postbaseline data are missing for Participant 3. Postbaseline and postintervention data are missing for Participant 7.

acknowledgment of tasks or skills as more challenging than previously thought (Participants 2, 3, 6, and 7); however, this emerging awareness of problems did not necessarily lead to broader awareness of implications for functioning in areas such as work or driving (Participant 7) or need for supervision (Participant 2). Growth was also evident in acknowledgment of progress or perceived improvement in abilities (Participants 3 and 6) and acknowledgment of need for therapy (Participants 4 and 6). One participant decided to prematurely return to fulltime studies during the program (Participant 2), which was reported to be very challenging and was associated with an increase in anxiety and depression symptoms at this time. Participant 5 had no interview content about self-awareness; however, MPAI-4 ratings indicated growth in self-awareness.

\section{Discussion}

All participants in this study, with the exception of one, identified occupational performance problems using the COPM; established their program goals with varying 


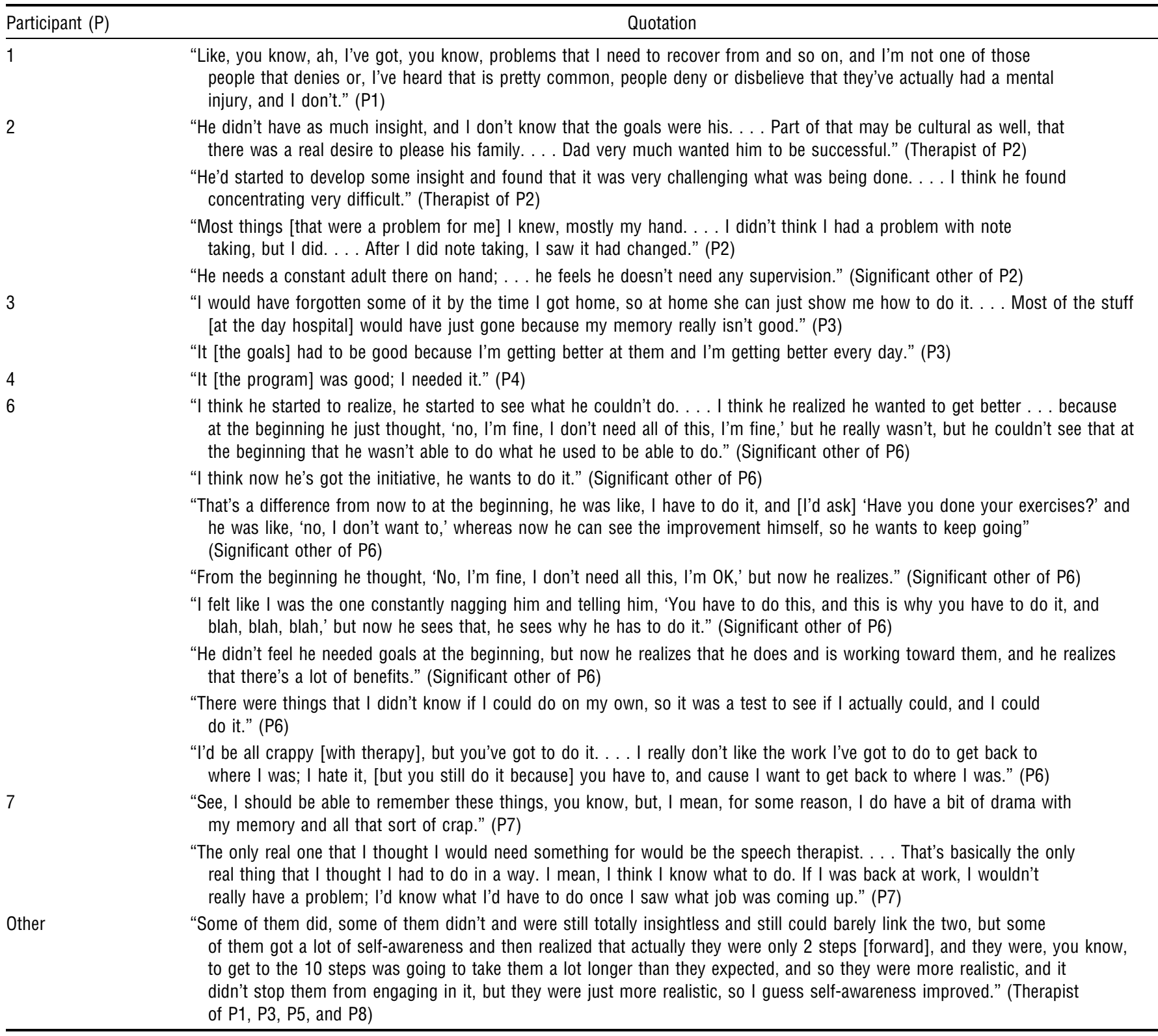

levels of input from their significant others and therapists; and perceived their goals as important, meaningful, and set by themselves. Previous research on goal-planning practice in inpatient settings after stroke indicates that a clientcentered process is often not practiced, and goals are often therapist driven and influenced by discharge priorities (Leach, Cornwell, Fleming, \& Haines, 2010; Levack, Dean, Siegert, \& McPherson, 2011). Because this program was a research intervention, the goal-planning process was less affected by factors that may influence goal setting in a clinical context. The participants' priority goals were endorsed if they were safe and able to be worked on in the program (i.e., within the bounds of available resources and expertise of an occupational therapist). The influence of contextual factors such as rehabilitation time frames, perceived discharge priorities, and service provider atti- tudes on goal-planning practices should be a focus for future research.

In relation to the development of self-awareness, we found evidence of variable growth over the course of the intervention for 7 of the 8 participants. Additionally, group analysis of MPAI-4 scores indicated growth in selfawareness in response to the intervention in contrast to the baseline period, which suggests that the intervention may have assisted with the development of self-awareness as well as goal attainment. In most cases we found increased awareness of problems related to the experience of challenges or improvements in goal-related tasks but little evidence of growth in awareness of implications for broader functioning. In some cases, we saw growth in the realization of need for rehabilitation and improved motivation for and engagement in the rehabilitation process. 
Aspects of this intervention, including the use of meaningful occupation to target individual goals, experiential feedback, and verbal feedback, have previously shown promise for enhancing self-awareness and improving error detection and self-monitoring after ABI (Fleming et al., 2006; Ownsworth et al., 2006; Schmidt, Fleming, Ownsworth, \& Lannin, 2013).

Results of this case series suggest a relationship between participation in goal planning, motivation and engagement in rehabilitation, and outcomes, which has been demonstrated in previous research (Webb \& Glueckauf, 1994; Wressle et al., 2002) and is supported by goal-planning theory (Scobbie et al., 2011). For many participants, engagement in the program fostered progress in goal attainment alongside some improvements in self-awareness. Occupation-based rehabilitation provides an opportunity to facilitate graded challenges guided by task analysis, opportunities to experience gradual improvement in valued areas (Pendleton \& Schultz-Krohn, 2013), and opportunities to provide meaningful feedback within a supportive environment. It also promotes satisfaction with improvement (Doig et al., 2009). The importance of supported and graded challenges to promote positive progress and experience of success as well as support to overcome challenges was highlighted by Participant 2, who experienced increased anxiety and depression in the face of challenges that were too great.

\section{Limitations and Future Research}

This study was a descriptive analysis of a small case series; therefore, findings cannot necessarily be generalized to everyone with impaired self-awareness. In addition, validated assessments of self-awareness were not used to measure change in self-awareness, because the original study was not designed to measure awareness as an outcome. Motivation, memory, engagement, and mood were not measured using validated neuropsychological assessment tools. Rather, they were gleaned from clinical impression and the report of participants' familiar therapists and significant others, proving it difficult to determine whether the accuracy of participants' self-report was limited by memory. The validity and reliability of the C-COGS are also yet to be established.

Use of the MPAI-4 participant and significant-other ratings to measure discrepancy scores, however, is the same method used to assess intellectual awareness using established measures such as the Awareness Questionnaire (Sherer, Bergloff, Boake, High, \& Levin, 1998) and Patient Competency Rating Scale (Prigatano \& Klonoff, 1998). Moreover, qualitative interview and field note data, which detailed each participant's journey, supplemented the MPAI-4 discrepancy data and in many cases gave insight into self-awareness, which was not reflected by participant discrepancy scores (Participants 3, 4, and 6). This result highlights the value of a mixed-methods approach and the importance of using multiple measures, particularly when measuring the complex concept of selfawareness. The postintervention interviews did not include specific questions about self-awareness; rather, participants raised these points freely during interviews, suggesting that they may have been particularly important to them.

In this study, we incorporated measures of intellectual awareness, or the person's self-knowledge of their abilities, which is subject to limitations of self-report by participants and significant others. For example, initial ratings by significant others may have been inflated because of lack of time with the injured person, who had just been discharged from hospital. Self-awareness also encompasses online awareness, which is a person's ability to monitor and modify behavior during performance; however, online awareness was not measured in this study. Online awareness is best assessed through observation of task performance (e.g., error detection, error correction; Hart, Giovannetti, Montgomery, \& Schwartz, 1998; Ownsworth et al., 2006). Online awareness is important to consider in future studies because of its impact on safety and independence.

Given the value of client-centered practice for enhancing participation of patients in multidisciplinary rehabilitation (Wressle, Lindstrand, Neher, Marcusson, \& Henriksson, 2003), future research should also seek to understand how patient and contextual factors mediate client-centered goal planning and rehabilitation. To best understand the utility, effectiveness, and potential for translation of treatment programs, research trialing interventions should ideally be implemented within real-world clinical practice. Studies using a single case experimental design in which the effectiveness of an intervention in individual cases can be systematically evaluated (Perdices $\&$ Tate, 2009; Tate, Taylor, \& Aird, 2013) are ideally suited to complex, heterogenous populations such as people with TBI for whom one intervention may not necessarily fit all.

\section{Implications for Occupational Therapy Practice}

Most participants in this study, despite moderate or severe impairment of self-awareness, were able to identify problems with occupational performance and work with an occupational therapist to set meaningful and important goals. Engagement in occupation-based, goal-directed rehabilitation appeared to have some benefits for some participants to foster 
awareness of injury-related changes to varying extents by providing experiences of unexpected challenges as well as unexpected improvement. The experience of improvement in meaningful occupations was motivating for some participants and resulted in enhanced engagement in rehabilitation. Our findings have the following implications for occupational therapy practice:

- The COPM can be used with people with impaired self-awareness to identify meaningful rehabilitation goals. People experiencing difficulty identifying occupational performance areas using the COPM were able to agree to work on goals identified with input to identify occupational performance problems by significant others and therapists.

- Engagement in occupation-based rehabilitation that targets goals that are meaningful and important to the client provides opportunities for graded, supported challenges.

- The experience of unexpected challenges as well as unexpected improvements in meaningful occupations can have benefits for enhancing self-awareness and engagement in rehabilitation.

\section{References}

Cheng, S. K. W., \& Man, D. W. K. (2006). Management of impaired self-awareness in persons with traumatic brain injury. Brain Injury, 20, 621-628. http://dx.doi.org/10.1080/ 02699050600677196

Cohen, J. (1988). Statistical power analysis for the behavior sciences (2nd ed.). Hillsdale, NJ: Erlbaum.

Doig, E. J., Fleming, J., Cornwell, P. L., \& Kuipers, P. (2009). Qualitative exploration of a client-centered, goal-directed approach to community-based occupational therapy for adults with traumatic brain injury. American Journal of Occupational Therapy, 63, 559-568. http://dx.doi.org/ 10.5014/ajot.63.5.559

Doig, E. J., Fleming, J., Kuipers, P., \& Cornwell, P. L. (2010). Clinical utility of the combined use of the Canadian Occupational Performance Measure and Goal Attainment Scaling. American Journal of Occupational Therapy, 64, 904-914. http://dx.doi.org/10.5014/ajot.2010.08156

Doig, E. J., Fleming, J., Kuipers, P., Cornwell, P., \& Khan, A. (2011). Goal-directed outpatient rehabilitation following TBI: A pilot study of programme effectiveness and comparison of outcomes in home and day hospital settings. Brain Injury, 25, 1114-1125. http://dx.doi.org/10.3109/ 02699052.2011 .607788

Ergh, T. C., Rapport, L. J., Coleman, R. D., \& Hanks, R. A. (2002). Predictors of caregiver and family functioning following traumatic brain injury: Social support moderates caregiver distress. Journal of Head Trauma Rehabilitation, 17, 155-174. http://dx.doi.org/10.1097/00001199200204000-00006

Fischer, S., Gauggel, S., \& Trexler, L. E. (2004). Awareness of activity limitations, goal setting and rehabilitation out- come in patients with brain injuries. Brain Injury, 18, 547-562. http://dx.doi.org/10.1080/02699050310001645793

Fleming, J. M., Lucas, S. E., \& Lightbody, S. (2006). Using occupation to facilitate self-awareness in people who have acquired brain injury: A pilot study. Canadian Journal of Occupational Therapy, 73, 44-55.

Fleming, J., \& Strong, J. (1995). Self-awareness of deficits following acquired brain injury: Considerations for rehabilitation. British Journal of Occupational Therapy, 58, 55-60.

Fleming, J. M., Strong, J., \& Ashton, R. (1996). Self-awareness of deficits in adults with traumatic brain injury: How best to measure. Brain Injury, 10, 1-15. http://dx.doi.org/10. 1080/026990596124674

Fleming, J. M., Strong, J., \& Ashton, R. (1998). Cluster analysis of self-awareness levels in adults with traumatic brain injury and relationship to outcome. Journal of Head Trauma Rehabilitation, 13, 39-51. http://dx.doi.org/10.1097/ 00001199-199810000-00006

Goverover, Y., Johnston, M. V., Toglia, J., \& Deluca, J. (2007). Treatment to improve self-awareness in persons with acquired brain injury. Brain Injury, 21, 913-923. http://dx. doi.org/10.1080/02699050701553205

Graneheim, U. H., \& Lundman, B. (2004). Qualitative content analysis in nursing research: Concepts, procedures and measures to achieve trustworthiness. Nurse Education Today, 24, 105-112. http://dx.doi.org/10.1016/j.nedt.2003.10.001

Hart, T., Giovannetti, T., Montgomery, M. W., \& Schwartz, M. F. (1998). Awareness of errors in naturalistic action after traumatic brain injury. Journal of Head Trauma Rehabilitation, 13, 16-28. http://dx.doi.org/10.1097/00001199199810000-00004

Jenkinson, N. T., Ownsworth, T., \& Shum, D. (2007). Utility of the Canadian Occupational Performance Measure in communitybased brain injury rehabilitation. Brain Injury, 21, 1283-1294. http://dx.doi.org/10.1080/02699050701739531

Kiresuk, T. J., Smith, A., \& Cardillo, J. E. (1994). Goal Attainment Scaling: Applications, theory and measurement. Hillsdale, NJ: Erlbaum.

Lam, C. S., McMahon, B. T., Priddy, D. A., \& Gehred-Schultz, A. (1988). Deficit awareness and treatment performance among traumatic head injury adults. Brain Injury, 2, 235-242. http://dx.doi.org/10.3109/02699058809150947

Landa-Gonzalez, B. (2001). Multicontextual occupational therapy intervention: A case study of traumatic brain injury. Occupational Therapy International, 8, 49-62. http://dx.doi.org/ 10.1002/oti.131

Law, M., Baptiste, S., Carswell, A., McColl, M., Polatajko, H., \& Pollock, N. (1994). Canadian Occupational Performance Measure Manual (2nd ed.). Toronto: CAOT Publications ACE.

Law, M., Cooper, B., Strong, S., Stewart, D., Rigby, P., \& Letts, L. (1996). The person-environment-occupation model: A transactive approach to occupational performance. Canadian Journal of Occupational Therapy. Revue Canadienne d'Ergotherapie, 63, 9-23. http://dx.doi.org/10.1177/ 000841749606300103

Leach, E., Cornwell, P., Fleming, J., \& Haines, T. (2010). Patient centered goal-setting in a subacute rehabilitation setting. Disability and Rehabilitation, 32, 159-172. http:// dx.doi.org/10.3109/09638280903036605 
Levack, W. M. M., Dean, S. G., Siegert, R. J., \& McPherson, K. M. (2011). Navigating patient-centered goal setting in inpatient stroke rehabilitation: How clinicians control the process to meet perceived professional responsibilities. $\mathrm{Pa}$ tient Education and Counseling, 85, 206-213. http://dx. doi.org/10.1016/j.pec.2011.01.011

Malec, J. F. (2001). Impact of comprehensive day treatment on societal participation for persons with acquired brain injury. Archives of Physical Medicine and Rehabilitation, 82, 885-895. http://dx.doi.org/10.1053/apmr.2001.23895

Malec, J. F., \& Lezak, M. D. (2008). Manual for the MayoPortland Adaptability Inventory (MPAI-4) for adults, children, and adolescents. Retrieved from http://tbims.org/combi/ mpai/manual.pdf

Malec, J. F., \& Thompson, J. M. (1994). Relationship of the Mayo-Portland Adaptability Index to functional outcome and cognitive performance measures. Journal of Head Trauma Rehabilitation, 9, 1-15. http://dx.doi.org/10.1097/ 00001199-199412000-00003

McColl, M. A., Paterson, M., Davies, D., Doubt, L., \& Law, M. (2000). Validity and community utility of the Canadian Occupational Performance Measure. Canadian Journal of Occupational Therapy, 67, 22-30. http://dx.doi.org/10.1177/ 000841740006700105

Ownsworth, T., \& Clare, L. (2006). The association between awareness deficits and rehabilitation outcome following acquired brain injury. Clinical Psychology Review, 26, 783-795. http://dx.doi.org/10.1016/j.cpr.2006.05.003

Ownsworth, T., Fleming, J., Desbois, J., Strong, J., \& Kuipers, P. (2006). A metacognitive contextual intervention to enhance error awareness and functional outcome following traumatic brain injury: A single-case experimental design. Journal of the International Neuropsychological Society, 12, 54-63. http://dx.doi.org/10.1017/S135561770606005X

Ownsworth, T., Quinn, H., Fleming, J., Kendall, M., \& Shum, D. (2010). Error self-regulation following traumatic brain injury: A single case study evaluation of metacognitive skills training and behavioural practice interventions. Neuropsychological Rehabilitation, 20, 59-80. http://dx.doi.org/10. 1080/09602010902949223

Pendleton, H. M., \& Schultz-Krohn, W. (2013). Pedretti's occupational therapy: Practice skills for physical dysfunction (7th ed.). St. Louis, MO: Mosby/Elsevier.

Perdices, M., \& Tate, R. L. (2009). Single-subject designs as a tool for evidence-based clinical practice: Are they unrecognised and undervalued? Neuropsychological Rehabilitation, 19, 904-927. http://dx.doi.org/10.1080/09602010903040691

Prigatano, G. P., \& Klonoff, P. S. (1998). A clinician's rating scale for evaluating impaired self-awareness and denial of disability after brain injury. Clinical Neuropsychologist, 12, 56-67. http://dx.doi.org/10.1076/clin.12.1.56.1721

Schmidt, J., Fleming, J., Ownsworth, T., \& Lannin, N. A. (2013). Video feedback on functional task performance improves self-awareness after traumatic brain injury: A randomized controlled trial. Journal of Neurorehabilitation and Neural Repair, 27, 316-324. http://dx.doi.org/10. $1177 / 1545968312469838$

Schmidt, J., Lannin, N., Fleming, J., \& Ownsworth, T. (2011). Feedback interventions for impaired self-awareness following brain injury: A systematic review. Journal of Rehabilitation Medicine, 43, 673-680. http://dx.doi.org/10.2340/ 16501977-0846

Scobbie, L., Dixon, D., \& Wyke, S. (2011). Goal setting and action planning in the rehabilitation setting: Development of a theoretically informed practice framework. Clinical Rehabilitation, 25, 468-482. http://dx.doi.org/10.1177/ 0269215510389198

Sherer, M., Bergloff, P., Boake, C., High, W., Jr., \& Levin, E. (1998). The Awareness Questionnaire: Factor structure and internal consistency. Brain Injury, 12, 63-68. http:// dx.doi.org/10.1080/026990598122863

Sherer, M., Bergloff, P., Levin, E., High, W. M., Jr., Oden, K. E., \& Nick, T. G. (1998). Impaired awareness and employment outcome after traumatic brain injury. Journal of Head Trauma Rehabilitation, 13, 52-61. http://dx.doi. org/10.1097/00001199-199810000-00007

Simmond, M., \& Fleming, J. (2003). Reliability of the selfawareness of deficits interview for adults with traumatic brain injury. Brain Injury, 17, 325-337. http://dx.doi. org/10.1080/0269905021000013219

Tate, R. L., Taylor, C., \& Aird, V. (2013). Applying empirical methods in clinical practice: Introducing the model for assessing treatment effect. Journal of Head Trauma Rehabilitation, 28, 77-88. http://dx.doi.org/10.1097/HTR.0b013e31824e103e

Toglia, J., Johnston, M. V., Goverover, Y., \& Dain, B. (2010). A multicontext approach to promoting transfer of strategy use and self regulation after brain injury: An exploratory study. Brain Injury, 24, 664-677. http://dx.doi.org/10. 3109/02699051003610474

Toglia, J., \& Kirk, U. (2000). Understanding awareness deficits following brain injury. NeuroRehabilitation, 15, 57-70.

Webb, P. M., \& Glueckauf, R. L. (1994). The effects of direct involvement in goal setting on rehabilitation outcome for persons with traumatic brain injuries. Rehabilitation Psychology, 39, 179-188. http://dx.doi.org/10.1037/h0080321

Wise, K., Ownsworth, T., \& Fleming, J. (2005). Convergent validity of self-awareness measures and their association with employment outcome in adults following acquired brain injury. Brain Injury, 19, 765-775. http://dx.doi. org/10.1080/0269905050019977

Wressle, E., Eeg-Olofsson, A. M., Marcusson, J., \& Henriksson, C. (2002). Improved client participation in the rehabilitation process using a client-centred goal formulation structure. Journal of Rehabilitation Medicine, 34, 5-11. http://dx.doi. org/10.1080/165019702317242640

Wressle, E., Lindstrand, J., Neher, M., Marcusson, J., \& Henriksson, C. (2003). The Canadian Occupational Performance Measure as an outcome measure and team tool in a day treatment programme. Disability and Rehabilitation, 25, 497-506. http://dx.doi.org/10.1080/0963828031000090560

Zakzanis, K. K. (2001). Statistics to tell the truth, the whole truth, and nothing but the truth: Formulae, illustrative numerical examples, and heuristic interpretation of effect size analyses for neuropsychological researchers. Archives of Clinical Neuropsychology, 16, 653-667. http://dx.doi.org/ 10.1093/arclin/16.7.653 
Reproduced with permission of the copyright owner. Further reproduction prohibited without permission. 